\title{
Frações físicas da matéria orgânica e carbono mineralizável do solo em fragmentos florestais do bioma Cerrado
}

O objetivo do estudo foi quantificar as frações físicas-granulométricas da matéria orgânica e o carbono mineralizável do solo de fragmentos florestais do bioma Cerrado nos municípios de Aquidauana e Anastácio, MS. Foram coletadas amostras de solo em dois fragmentos florestais e áreas de pastagem permanente (PP) ao entorno. Para os fragmentos, as amostras foram coletadas em 3 pontos internos: borda do fragmento (BO), metade do raio (MR) e centro do fragmento (CF), além de um ponto no entorno dos fragmentos, em áreas de pastagem permanente (PP). Foram determinados os teores de carbono orgânico total (COT), carbono da matéria orgânica particulada (C-MOP) e mineral (C-MOM), com posteriores cálculos de seus respectivos estoques, além do índice de estoque de carbono (IEC) labilidade (L), índice de labilidade (IL) e índice de manejo de carbono (IMC), e análise de carbono mineralizável (C-CO2). Os maiores teores de COT foram apresentados no ponto MR 23,77 g kg-1 no fragmento 1, e nos pontos BO 16,41 g kg-1 e CF 16,18 g kg-1 do fragmento 2 . Os maiores teores de C-MOP foram observados na camada superficial, com aumento de C-MOM em função do aumento da profundidade, chegando a 86\% de representatividade. A emissão total de $\mathrm{C}-\mathrm{CO} 2$ indicou as maiores emissões nos pontos $\mathrm{BO}$ no fragmento 1 e BO e MR no fragmento 2. A conversão de áreas nativas em PP não influenciou no COT. Houve maior representatividade de C-MOM em relação a C-MOP, porém a conversão de áreas nativas em PP comprometeu a atividade microbiana do solo.

Palavras-chave: Emissão de C-CO2; Índice de manejo de carbono; Labilidade da matéria orgânica.

\section{Physical fractions of organic matter and mineralizable carbon of the soil in forest fragments of the Cerrado biome}

\begin{abstract}
The objective of the study was to quantify the physical-granulometric fractions of organic matter and the mineralizable carbon of the soil from forest fragments of the Cerrado biome in the municipalities of Aquidauana and Anastácio, MS. Soil samples were collected in two forest fragments and areas of permanent pasture (PP) around. For fragments, samples were collected at 3 internal points: fragment edge (FE), half radius (HR) and fragment center (FC), plus a point around the fragments, in areas of permanent pasture (PP). The levels of total organic carbon (TOC), carbon of particulate organic matter (C-POM) and mineral (C-MOM) were determined, with subsequent calculations of their respective stocks, in addition to the carbon stock index (CSI), lability (L), lability index (LI) and carbon management index (CMI), and analysis of mineralizable carbon (C-CO2). The highest levels of TOC were presented at point HR $23.77 \mathrm{~g} \mathrm{~kg}-1$ in fragment 1, and at points FE 16.41 $\mathrm{g} \mathrm{kg}-1$ and FC $16.18 \mathrm{~g} \mathrm{~kg}-1$ in fragment 2. The highest levels of C-POM were observed in the superficial layer, with an increase in C-MOM due to an increase in depth, reaching $86 \%$ of representativeness. The total emission of C-CO2 indicates as greater amounts at points FE on fragment 1 and FE and HR on fragment 2. The conversion of native areas into PP did not influence TOC. There was a greater representativeness of C-MOM in relation to C-POM, however the conversion of native areas to PP compromised the microbial activity of the soil.
\end{abstract}

Keywords: C-CO2 emission; Carbon index; Organic matter lability.

Jefferson Matheus Barros Ozório (iD) Universidade Estadual de Mato Grosso do Sul, Brasil http://lattes.cnpq.br/4562421968469006

http://orcid.org/0000-0002-7836-7668 ozorio.jmb@outlook.com

Jean Sérgio Rosset

Universidade Estadual de Mato Grosso do Sul, Brasil http://lattes.cnpq.br/0419077354773649 http://orcid.org/0000-0003-2214-2694 rosset@uems.br

\section{Jolimar Antonio Schiavo (iD)}

Universidade Estadual de Mato Grosso do Sul, Brasil http://lattes.cnpq.br/6847795121765024 http://orcid.org/0000-0003-0061-4726 schiavo@uems.br
Camila Beatriz da Silva Souza (iD

Universidade Estadual de Mato Grosso do Sul, Brasil http://lattes.cnpq.br/7836151524551588 http://orcid.org/0000-0002-7186-1014 camilabeatrizss@hotmail.com

\section{Paulo Guilherme da Silva Farias (it)}

Universidade Estadual de Mato Grosso do Sul, Brasil http://lattes.cnpq.br/5627503318732435

http://orcid.org/0000-0003-4708-2122 pauloguilhermesf@hotmail.com

Roniedison da Silva Menezes

Universidade Estadual de Mato Grosso do Sul, Brasil ttp://lattes.cnpq.br/0419077354773649 http://orcid.org/0000-0003-3778-1878 roniedison1@hotmail.com
Naelmo de Souza Oliveira (iD)

Universidade Estadual de Mato Grosso do Sul, Brasil http://lattes.cnpq.br/8993834368969627

http://orcid.org/0000-0002-4062-880X naelmo-95@hotmail.com

\section{Elói Panachuki iD}

Universidade Estadual de Mato Grosso do Sul, Brasil http://lattes.cnpq.br/4598968727968646 http://orcid.org/0000-0002-5816-7466 eloip@uems.br 


\section{INTRODUÇÃO}

Os fatores históricos de colonização, atividades antrópicas e crescimento populacional possuem influencia na ocorrência da fragmentação de grandes extensões de matas nativas. Essa fragmentação promove distúrbios ao ambiente provocando alterações na paisagem em geral (NOVAIS et al., 2016; VIANA et al., 1998; BARROS et al., 2016). Os efeitos da fragmentação permitem que a matriz da paisagem seja composta por áreas agrícolas e outras formas de uso, que provocam no ambiente edáfico, alterações no fluxo de radiação, água e nutrientes (OLIVEIRA et al., 2015; SAUNDERS et al., 1991).

Essas atividades antrópicas na vegetação nativa em nível de Brasil aconteceram em todos os biomas. O Cerrado brasileiro foi um dos biomas que mais sofreu com os avanços da agropecuária, reduzindo muitas de suas extensas áreas, em fragmentos de variadas formas e extensões (DALMOLIN et al., 2013). Essa conversão de áreas nativas acaba por comprometer a qualidade do ambiente edáfico de diferentes formas em função da região, tipo de solo, clima, vegetação, forma de uso, entre outros fatores (SALES et al., 2018; SOUZA et al., 2017; BARBOSA et al., 2018).

A qualidade do solo (QS) é complexa e se baseia na capacidade do mesmo em sustentar os serviços ecossistêmicos, mantendo equilíbrio na qualidade física, química e biológica, além de ser totalmente dependente do sistema de manejo adotado, bem como a relação entre o ecossistema e o ambiente (DORAN et al., 1994). O estudo de QS foi aprimorado por vários autores, que desenvolveram métodos e índices de qualidade, que permitem aplicar-se de forma distinta para diferentes tipos de solos e regiões. Os indicadores aplicados devem ser sensíveis ao manejo e uso do ambiente edáfico, sendo eficientes e precisos em identificar alterações nos atributos do solo também em curto período de avaliação (AZIZ et al., 2013; LAL, 2018; MARQUES et al., 2015; MAGALHÃES et al., 2016; PINTO JUNIOR et al., 2018).

A materia orgânica do solo (MOS), através da determinação do conteúdo de carbono (C) orgânico, é um dos indicadores sensíveis em detectar alterações na qualidade do ambiente edáfico (ASSUNÇÃO et al., 2019; BORGES et al., 2015; ROSSET et al., 2019) Esta relacionada com vários aspectos de qualidade do mesmo, citando-se a contribuição no aumento da resistência do solo a ação dos processos erosivos (GUIMARÃES et al., 2012), elevação da taxa de infiltração de água no solo (SOUZA et al., 2017), promoção da estabilidade de agregados do solo pela ação cimentante (FERREIRA et al., 2020; TISDALL et al., 1982; OBOUR et al., 2018; RAMOS et al., 2018), aumento da porosidade do solo (LAL, 2018; LIANG et al., 2019) e diminuição da compactação (FERREIRA et al., 2018; REIS et al., 2018).

A dinâmica da MOS é muito discutida pelo papel que o solo desempenha no sequestro de $C$ atmosférico, mitigando os efeitos de alterações climáticas em niveis globais e promoção do aumento da estocagem de $C$ no solo (MARQUES et al., 2015; MAGALHÃES et al., 2016). Em ambientes naturais o estoque de $C$ encontra-se em equilíbrio entre as taxas de entrada e saída, e quando apresentam algum tipo de perturbação que influencie na deposição de serapilheira (BARROS et al., 2016), acaba por modificar a dinâmica do estoque de C nessas áreas (LOSS et al., 2015; KOVEN et al., 2017; REIS et al., 2019). Porém, em muitos casos, somente a quantificação do $C$ não é suficiente para identificação de possíveis modificações na 
qualidade do ambiente edáfico (SINGOR et al., 2014).

As técnicas de fracionamento da MOS são importantes para avaliação de uso do solo, por serem sensiveis em detectar modificações na qualidade edáfica, mesmo em um curto periodo de tempo (LOSS et al., 2015; ROMANIW et al., 2015), e por ter estreita relação com os atributos do solo (BALDOTTO et al., 2010). Dentre as técnicas, o fracionamento fisico-granulometrico se destaca, por permitir uma avaliação da qualidade da MOS através da quantificação das frações lábeis e recalcitrantes da fração orgânica do solo (RANGEL et al., 2007).

A avaliação de atividade microbiana através da taxa de emissão de dióxido de carbono $\left(\mathrm{CO}_{2}\right)$, também se configura como importante ferramenta para avaliação da sustentabilidade de um ambiente natural ou manejado (SOUZA et al., 2010; LOSS et al., 2013; REIS et al., 2019; ROSSET et al., 2019), uma vez que a adição de quantidades consideraveis de C estimula a atividade desses microrganismos (KUZYAKOV et al., 2000; LOSS et al., 2013; BORGES et al., 2015; WADE et al., 2018) com vistas na melhoria da qualidade edáfica (LOSS et al., 2013).

Com a justificativa de conhecer as diferentes frações do carbono em fragmentos de vegetação natural em um importante bioma brasileiro, o trabalho objetivou quantificar as frações físicasgranulométricas da matéria orgânica do solo, o carbono mineralizável e determinar os índices de manejo de carbono de diferentes pontos internos de fragmentos florestais e áreas manejadas aos seus entornos, no bioma Cerrado.

\section{METODOLOGIA}

\section{Localização, Clima, Solo e Histórico das Áreas de Estudo}

Foram coletadas amostras de solos em dois fragmentos florestais, localizados nos municípios de Aquidauana e Anastácio, no bioma Cerrado, estado de Mato Grosso do Sul (Figura 1, Tabela 1). 0 clima da região é classificado como Aw (Tropical úmido), sendo que a vegetação de ambas as áreas, apresentam características de Cerradão (SILVA JUNIOR, 2005).

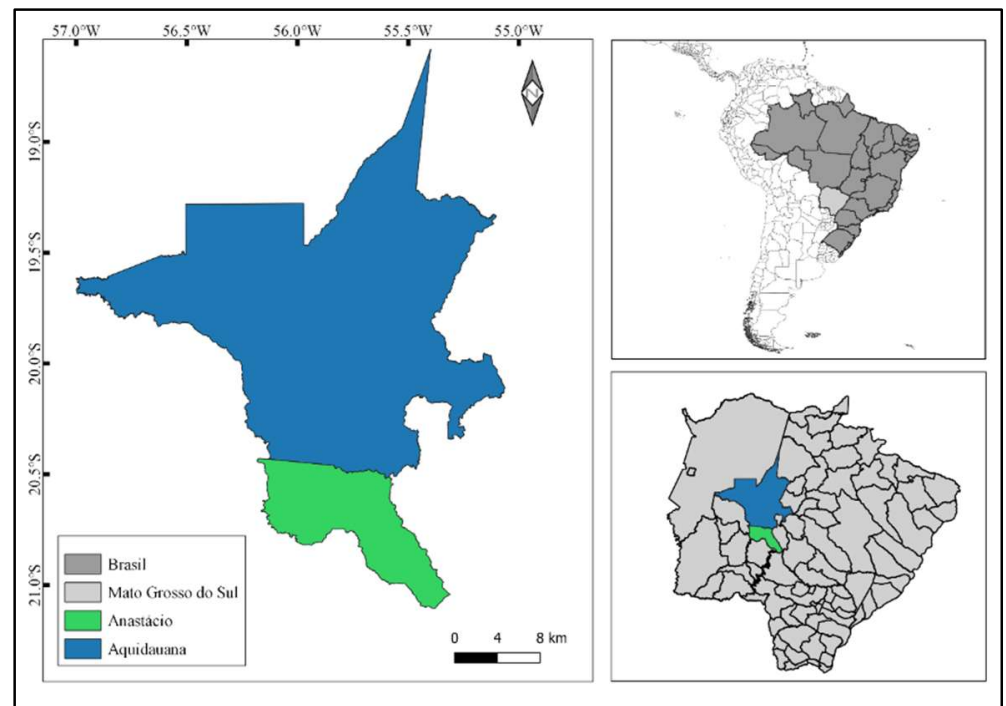

Figura 1: Mapa de localização dos municípios de Aquidauana e Anastácio - MS, Brasil. 
Tabela 1: Descrições das áreas dos fragmentos florestais avaliados.

\begin{tabular}{ll}
\hline Bioma Cerrado & Descrição \\
\hline Fragmento 1 & 55,7 ha; 209 m de altitude, 2025'58,46' Sul (S) e 5541'35,29” Oeste (O). \\
Fragmento 2 & 77,3 ha; 227 m de altitude, 2031'12,48” Sul (S) e 5541'09,25" Oeste (O). \\
\hline
\end{tabular}

O solo predominante nos dois municípios onde se encontram os fragmentos é classificado como Argissolo Vermelho-Amarelo (SANTOS et al., 2013) de textura média $\left(762,9,56,7,180,4 \mathrm{~g} \mathrm{~kg}^{-1}\right.$ de areia, silte e argila, respectivamente no fragmento 1, e $711,2,112,6$ e 176,2 $\mathrm{g} \mathrm{kg}^{-1}$ de areia, silte e argila, respectivamente no fragmento 2), sendo os dois fragmentos com formato retangular.

A área ao entorno do fragmento 1 encontra-se com pastagem permanente (Urochloa decumbens), com 420,7 ha, a qual foi instalada no ano de 1980 , sendo reformada com revolvimento de solo, calagem e adubação fosfatada no ano de 2008. Ao entorno do fragmento 2 também se encontra cultivos de PP (Urochloa decumbens), com 1.250 ha, instalada no ano de 1992, e reformada com revolvimento de solo, calagem e adubação fosfatada no ano de 2007. Ambas as áreas de pastagem apresentam sinais visíveis de degradação/mal manejo: baixo potencial de cobrimento do solo pela espécie forrageira, presença de plantas invasoras, além de lotação de animais com 1 unidade animal (UA) ha ${ }^{-1}$.

\section{Coletas de Amostras de Solo}

As coletas foram realizadas em quatro pontos, sendo três pontos no interior dos fragmentos e um ponto ao entorno dos mesmos. Os pontos correspondem à borda do fragmento (BO), ponto central entre a borda e o centro do fragmento, denominado de metade do raio (MR), centro do fragmento (CF) e pastagem permanente (PP) ao entorno dos fragmentos. A disposição dos pontos está descrita na Tabela 3. A caracterização química dos pontos estudados é apresentada na Tabela 2.

Tabela 3: Descrição dos pontos de coleta nos fragmentos e sua distância a partir da borda dos fragmentos.

\begin{tabular}{llll}
\hline & \multicolumn{3}{l}{ Fragmentos (distância (m) em relação à borda) } \\
\hline Ponto de coleta & Descrição do ponto & Fragmentos & $\mathbf{2}$ \\
\hline P. $\mathbf{1}$ & Centro do fragmento (CF) & $\mathbf{1}$ & 320 \\
P. $\mathbf{2}$ & Metade do raio do fragmento (MR) & 240 & 160 \\
P. $\mathbf{3}$ & Borda do fragmento (BO) & 120 & 0 \\
P. $\mathbf{1}$ & Fora do fragmento (SPD ou PP) & 0 & 320 \\
\hline
\end{tabular}

Tabela 2: Caracterização química dos pontos estudados nos fragmentos 1 e 2 e nas áreas de PP ao entorno.

\begin{tabular}{|c|c|c|c|c|}
\hline Determinações & $\begin{array}{l}\text { Pontos } \mathrm{BO}, \mathrm{MR} \text { e CF do } \\
\text { fragmento } 1\end{array}$ & $\begin{array}{l}\text { Pontos } \mathrm{BO}, \mathrm{MR} \text { e } \mathrm{CF} \text { do } \\
\text { fragmento } 2\end{array}$ & $\begin{array}{l}\text { PP ao entorno do } \\
\text { fragmento } 1\end{array}$ & $\begin{array}{l}\text { PP ao entorno do } \\
\text { fragmento } 2\end{array}$ \\
\hline $\mathrm{pH}\left(\mathrm{CaCl}_{2} 0,01 \mathrm{M}\right)$ & 4,06 & 4,53 & 4,11 & 4,62 \\
\hline $\mathrm{P}\left(\mathrm{mg} / \mathrm{dm}^{3}\right)$ & 2,86 & 2,76 & 1,68 & 1,68 \\
\hline $\mathrm{K}\left(\mathrm{cmol}_{\mathrm{c}} / \mathrm{dm}^{3}\right)$ & 0,11 & 0,15 & 0,03 & 0,06 \\
\hline $\mathrm{Ca}\left(\mathrm{cmol}_{\mathrm{c}} / \mathrm{dm}^{3}\right)$ & 0,30 & 1,30 & 0,40 & 0,80 \\
\hline $\mathrm{Mg}\left(\mathrm{cmol}_{\mathrm{c}} / \mathrm{dm}^{3}\right)$ & 0,20 & 0,70 & 0,20 & 0,60 \\
\hline $\mathrm{Al}\left(\mathrm{cmol}_{\mathrm{c}} / \mathrm{dm}^{3}\right)$ & 0,85 & 0,25 & 0,56 & 0,15 \\
\hline $\begin{array}{l}\mathrm{H}+\mathrm{Al} \\
\left.\mathrm{dm}^{3}\right)\end{array} \quad\left(\mathrm{cmol}_{\mathrm{c}} /\right.$ & 3,10 & 2,80 & 3,50 & 1,30 \\
\hline SB & 0,61 & 2,15 & 0,63 & 1,46 \\
\hline С.T.C (pH 7,0) & 3,71 & 4,95 & 4,13 & 2,76 \\
\hline V\% & 16,4 & 43,4 & 15,3 & 52,9 \\
\hline
\end{tabular}

Laboratório: NUTRISOLO, Ivinhema, MS. Caracterização química - Cloreto de Cálcio (pH); Mehlich (P e K); KCl 1N (Ca, Mg e Al); Acetato de Cálcio pH 7,0 (H + Al). SB: Soma por bases, C.T.C: Capacidade de troca catiônica, V\%: Saturação de bases. 
Para cada ponto de coleta foram realizadas 4 repetições em um raio de $20 \mathrm{~m}^{2}$. Foram coletadas amostras de solos deformadas e indeformadas no interior dos fragmentos, e nas áreas de PP ao entorno. As amostras indeformadas para avaliação da densidade do solo (Ds) foram coletadas com auxílio de anel volumétrico com volume de $48,86 \mathrm{~cm}^{3}$. As amostras compostas deformadas foram coletadas mediante coleta de três amostras simples, nas camadas de 0-0,05, 0,05-0,1 e 0,1-0,2 m. Partes das amostras deformadas da camada 0-0,05 m foram imediatamente colocadas sob refrigeração para análises de evolução de $\mathrm{C}^{-\mathrm{CO}_{2}}$ (carbono mineralizável).

\section{Análises Realizadas}

Após a coleta, as amostras deformadas foram secas ao ar, destorroadas e passadas em peneira $2 \mathrm{~mm}$ para obtenção da terra fina seca ao ar (TFSA). O carbono orgânico total (COT) foi determinado pela oxidação da matéria orgânica pelo dicromato de potássio, em meio sulfúrico sob aquecimento, e titulado com sulfato ferroso amoniacal (YEOMANS et al., 1988).

O fracionamento físico-granulométrico da MOS foi efetuado seguindo metodologia de Cambardella et al. (1992), em que $20 \mathrm{~g}$ de TFSA, juntamente com $60 \mathrm{ml}$ de hexametafosfato de sódio $\left(5 \mathrm{~g} \mathrm{~L}^{-1}\right)$ foram acondicionados em erlenmeyer de $250 \mathrm{ml}$, sendo agitados durante 16 horas em mesa agitadora a uma velocidade de $150 \mathrm{rpm}$. Após o período de agitação as amostras foram lavadas em peneira de $53 \mu \mathrm{m}$, sendo que o material retido na peneira consistiu na MOP (matéria orgânica particulada), obtendo-se posteriormente, pela metodologia de Yeomans et al. (1988), o carbono da matéria orgânica particulada (CMOP) e, através da diferença entre COT e C-MOP obteve-se o carbono da matéria orgânica mineral (C-MOM).

Posteriormente às determinações das frações de carbono, foram calculados os índices para avaliação da qualidade da MOS, sendo eles; o índice de estoque de carbono (IEC), labilidade da MOS (L), índice de labilidade (IL) e o índice de manejo de carbono (IMC), calculados segundo Blair et al. (1995). Para os cálculos de estoque de carbono da matéria orgânica particulada (EstC-MOP) e estoque de carbono da matéria orgânica mineral (EstC-MOM), foi determinada a densidade do solo de acordo com Claessen (1997), sendo os estoques calculados seguindo o método da massa equivalente (REIS et al., 2018; SIGNOR et al., 2014).

A análise de $\mathrm{C}-\mathrm{CO}_{2}$ liberado foi efetuada seguindo metodologia de Mendonça et al. (2005), na qual foram acondicionados $50 \mathrm{~g}$ de solo, um frasco com $30 \mathrm{ml}$ de solução de $\mathrm{NaOH} \mathrm{0,5} \mathrm{mol} \mathrm{L-1}$ para captar o C- $\mathrm{CO}_{2}$ emitido, e outro frasco com $30 \mathrm{ml}$ de $\mathrm{H}_{2} \mathrm{O}$, de forma a manter a umidade constante, no interior de um pote de plástico com capacidade de $3 \mathrm{~L}$, sendo o mesmo hermeticamente fechado. A cada dia de avaliação, do frasco de solução de $\mathrm{NaOH}$ foram retirados $10 \mathrm{ml}$, sendo adicionado $10 \mathrm{ml}$ da solução de $\mathrm{BaCl}_{2} 0,05 \mathrm{~mol} \mathrm{~L}^{-1} \mathrm{e}$ 4 gotas de fenolftaleína $1 \%$, com posterior titulação com $\mathrm{HCl}$ 0,25 $\mathrm{mol} \mathrm{L}^{-1}$. Após a retirada do frasco de $30 \mathrm{~mL}$ da solução de $\mathrm{NaOH} 0,5 \mathrm{~mol} \mathrm{~L}^{-1}$ de dentro do recipiente, um novo frasco com mais $30 \mathrm{~mL}$ era inserido para a próxima avaliação, tendo-se o cuidado de deixar o pote aberto por 15 minutos para a troca de ar, antes da próxima incubação. As titulações/avaliações foram realizadas em intervalos de $24 \mathrm{~h}$ nos primeiros 7 dias, de $48 \mathrm{~h}$ entre o $8^{\circ}$ e $17^{\circ}$ dia, e de $96 \mathrm{~h}$ entre o $18^{\circ}$ e $33^{\circ}$ dia, conforme efetuado por Loss et al. (2013) e Rosset 
et al. (2019).

Os resultados foram analisados quanto à normalidade e homogeneidade de variância através de teste de Shapiro-Wilk e Bartlett, respectivamente. Posteriormente, em delineamento inteiramente casualizado, os resultados foram submetidos à análise de variância com aplicação do teste $F$, de forma isolada, avaliando cada bioma e fragmento individualmente, e os valores médios comparados pelo teste de Tukey a 5\% com auxílio do programa R Core Team (2019), todos os testes foram realizados utilizando o pacote ExpDes.pt (FERREIRA et al., 2018)

\section{RESULTADOS E DISCUSSÃO}

Os teores de COT dos fragmentos do bioma Cerrado apresentaram padrões distintos. No fragmento 1, o ponto MR apresentou o maior teor, $23,77 \mathrm{~g} \mathrm{~kg}^{-1}$ na camada $0-0,05 \mathrm{~m}$, seguido dos pontos $\mathrm{BO}$ e CF com teores de 16,41 e 16,18 $\mathrm{g} \mathrm{kg}^{-1}$, respectivamente (Figura 2). No fragmento 2, o ponto CF apresentou o maior teor de COT, 17,76 $\mathrm{g} \mathrm{kg}^{-1}$ na camada 0-0,05 m. No fragmento 1, a área de PP ao entorno apresentou menor teor de COT na camada 0-0,05 m, padrão não observado na PP ao entorno do fragmento 2 . Já na camada 0,10-0,20 m não houveram diferenças entre os pontos internos e as áreas de PP avaliadas ao entorno dos fragmentos (Figura 2).

A semelhança nos teores de COT entre as áreas de PP e os pontos internos de ambos os fragmentos, especialmente na camada 0,10-0,20 m, pode ser explicada pela contribuição da biomassa radicular da pastagem que, ao se decompor, aumenta o teor de C em camadas subsuperficiais (SANTOS et al., 2019; STUMPF et al., 2018). Além de contribuir com o aumento dos teores de COT, as raizes de pastagens contribuem com a agregação (SALTON et al., 2008), diminuindo a compactação do solo (LAL, 2018).

A semelhança entre os teores de COT de alguns pontos dos fragmentos e as áreas de PP degradada ao entorno nas camadas $0-0,05 \mathrm{~m}$ do fragmento 2 , e $0,05-0,10$ do fragmento 1 , sugerem que os fragmentos deste bioma apresentam naturalmente baixos teores de COT, mesmo com deposição contínua de serapilheira, que contribui significativamente para os maiores teores de COT nas camadas mais superficiais, principalmente em áreas de vegetação natural, onde não se tem revolvimento do solo (LOSS et al., 2015; NOVAIS et al., 2016; ROSSET et al., 2014; 2016). Esses resultados contradizem com os apresentados por Silva et al. (2014), Resende et al. (2015) e Carvalho et al. (2018), que encontraram diminuição do teor de COT em áreas de pastagens comparados a áreas de Cerrado nativo, em camadas superficiais do solo.

Os maiores teores de C-MOP do fragmento 1 foram observados nos pontos $\mathrm{CF}, 5,21 \mathrm{~g} \mathrm{~kg}^{-1}$, e BO, 4,04 $\mathrm{g} \mathrm{kg}^{-1}$, na camada 0-0,05 m. Já na camada 0,10-0,20 m, os maiores teores desta fração foram observados na área de PP, 1,87 $\mathrm{g} \mathrm{kg}^{-1}$, e no ponto MR, $1,79 \mathrm{~g} \mathrm{~kg}^{-1}$ (Tabela 4). No fragmento 2, nas camadas de 0-0,05 m e 0,10-0,20 m, os pontos não diferiram entre si para o C-MOP, apresentando variação de 4,13 a 5,69 g kg-1 para camada 0-0,05 m, e de 1,87 a 2,92 $\mathrm{g} \mathrm{kg}^{-1}$ para a camada 0,10-0,20 m, sendo a área de PP com menor teor em relação aos pontos internos do fragmento na camada 0,05-0,10 m (Tabela 4). 


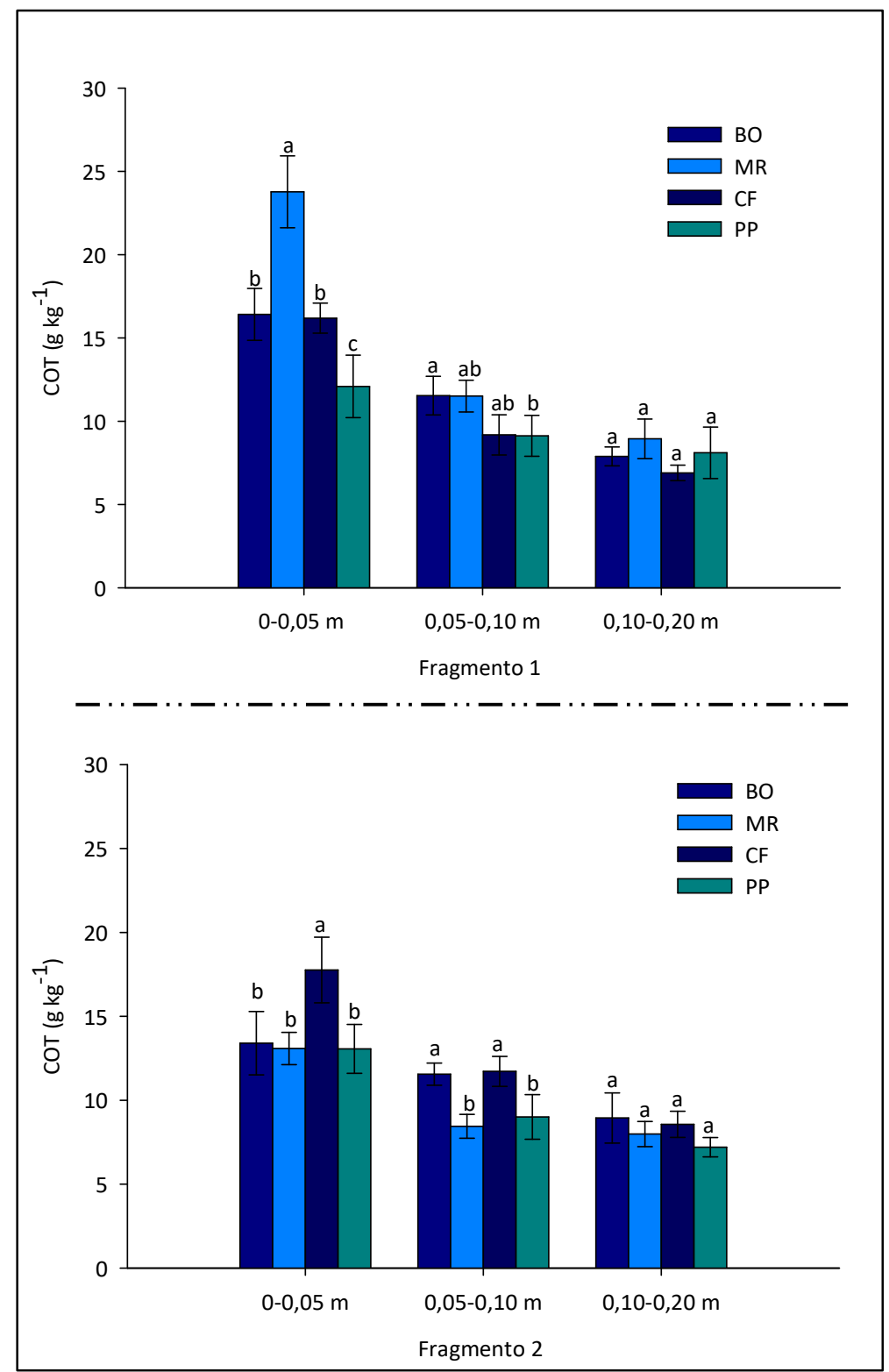

Figura 2: Carbono orgânico total (COT) dos diferentes pontos de coleta no interior e ao entorno dos fragmentos 1 e 2 do bioma Cerrado. *Médias seguidas de mesma para cada fragmento e camada não diferem estatisticamente pelo teste Tukey (5\%). BO: Borda do fragmento; MR: Metade do raio; CF: Centro do fragmento; PP: Pastagem Permanente. Traços nas barras representam o desvio padrão dos dados.

A semelhança de C-MOP nos pontos internos e as áreas de PP ao entorno dos fragmentos, pode estar relacionada a perturbação natural que o ambiente sofre, apresentando clareiras naturais que podem modificar determinados pontos internos destes fragmentos florestais (DIDHAM, 1998). Outro fator importante que contribui para menor deposição de serapilheira, são as variações de fitofisionomia apresentadas nas áreas de Cerrado stricto sensu para Cerradão, característicos de áreas mais abertas com presença de espécies arbustivas e maior incidência de gramíneas (MALHEIROS et al., 2016).

Porém, é importante ressaltar a contribuição da biomassa radicular da pastagem para os teores de C-MOP na camada 0,10-0,20 m. Esse fato contribui diretamente com a melhoria qualidade do solo ao longo do tempo, atuando na agregação (SANTOS et al., 2019; SALTON et al., 2008), e na diminuição da compactação do solo (STUMPF et al., 2018). Semelhanças entre áreas de pastagens permanentes e Cerrado nativo em camadas subsuperficiais, também foram relatados por Cardoso Junior et al. (2016) e Gmach et al. (2018). Entretanto, Oliveira et al. (2016) observaram maiores valores em pastagem bem manejadas, quando 
comparado a Cerrado nativo.

Tabela 4: Carbono da matéria orgânica particulada (C-MOP) e mineral (C-MOM), porcentagem de carbono da matéria orgânica particulada (\% MOP) e mineral (\% MOM), estoque de carbono da matéria orgânica particulada (Est. MOP) e mineral (Est. MOM) nos diferentes pontos de coleta no interior e ao entorno dos fragmentos 1 e 2 do bioma Cerrado.

\begin{tabular}{|c|c|c|c|c|c|c|c|c|c|c|c|c|}
\hline \multicolumn{7}{|c|}{ Fragmento 1} & \multicolumn{6}{|c|}{ Fragmento 2} \\
\hline & C-MOP & C-MOM & MOP & MOM & Est. MOP & Est. MOM & C-MOP & C-MOM & MOP & MOM & Est. MOP & Est. MOM \\
\hline & \multicolumn{2}{|c|}{$----\mathrm{g} \mathrm{kg}^{-1}-\mathrm{-o}^{--}$} & \multicolumn{2}{|c|}{----\%---- } & \multicolumn{2}{|c|}{---Mg ha-1--- } & \multicolumn{2}{|c|}{----g kg-1--- } & \multicolumn{2}{|l|}{----\%---- } & \multicolumn{2}{|c|}{$---M g$ ha-1--- } \\
\hline \multicolumn{13}{|c|}{$0-0,05 \mathrm{~m}$} \\
\hline $\mathrm{BO}$ & $4,04 a b$ & $12,36 \mathrm{~b}$ & $24,76 a b$ & $75,23 a b$ & $2,50 a$ & $7,62 b$ & $5,30 a$ & $8,09 a b$ & $39,95 a$ & $60,04 a$ & $3,77 a$ & $5,78 a$ \\
\hline MR & $3,54 b$ & $20,22 a$ & $15,16 b$ & $84,83 a$ & $2,22 a$ & $12,53 a$ & $5,11 a$ & $7,96 b$ & $39,25 a$ & $60,74 a$ & $3,10 a$ & $5,75 a$ \\
\hline CF & $5,21 a$ & $10,97 b$ & $32,27 a$ & $67,72 b$ & $3,31 a$ & $6,96 b$ & 5,69a & $12,06 a$ & $32,54 a$ & $67,45 a$ & $3,92 a$ & $8,38 a$ \\
\hline PP & $3,02 b$ & $9,06 b$ & $25,73 a b$ & $74,26 a b$ & $2,31 a$ & $6,89 \mathrm{~b}$ & 4,13a & $8,92 a b$ & $32,19 a$ & $67,80 a$ & $3,57 a$ & $7,78 a$ \\
\hline CV(\%) & 18,71 & 15,24 & 23,41 & 6,63 & 23,58 & 13,48 & $\begin{array}{l}17,04 \\
\end{array}$ & 21,08 & 20,57 & 12,61 & 16,20 & 23,92 \\
\hline \multicolumn{13}{|c|}{$0,05-0,10 \mathrm{~m}$} \\
\hline BO & $1,87 a$ & $9,66 a$ & $16,33 a$ & $83,61 a$ & $1,21 b$ & $6,17 a$ & $3,86 a$ & $7,69 a$ & $33,56 a b$ & $66,43 a b$ & $2,81 a$ & $5,60 a$ \\
\hline MR & $2,24 a$ & $9,25 a b$ & $19,47 a$ & $80,52 a$ & $1,48 a b$ & $6,10 a$ & $\begin{array}{l}3,62 a \\
3\end{array}$ & $4,82 b$ & $42,99 a$ & $57,00 b$ & $2,67 a$ & $3,55 a$ \\
\hline $\mathrm{CF}$ & $2,16 a$ & $7,01 a b$ & $24,38 a$ & $75,60 a$ & $1,32 b$ & $4,51 a$ & $\begin{array}{l}3,62 a \\
\end{array}$ & $8,09 a$ & $31,10 b$ & $68,89 a$ & $2,43 a$ & $5,47 a$ \\
\hline PP & $2,51 a$ & $6,60 \mathrm{~b}$ & $28,00 a$ & $71,99 a$ & $1,91 a$ & $4,99 a$ & $2,50 b$ & $6,50 a b$ & $28,46 \mathrm{~b}$ & $71,53 a$ & $2,08 a$ & $5,41 a$ \\
\hline CV(\%) & 15,78 & 15,69 & 25,67 & 7,27 & 18,57 & 18,74 & 12,35 & 16,11 & 15,95 & 8,23 & 15,17 & 20,43 \\
\hline \multicolumn{13}{|c|}{$0,10-0,20 \mathrm{~m}$} \\
\hline $\mathrm{BO}$ & $1,32 \mathrm{bc}$ & $6,56 a$ & $16,81 a$ & $83,18 a$ & $1,86 b c$ & $9,20 a$ & $2,92 a$ & $6,02 a$ & $33,98 a$ & $66,01 a$ & $4,37 a$ & $9,06 a$ \\
\hline$M R$ & $1,79 a b$ & $7,14 a$ & $20,33 a$ & $79,66 a$ & $2,41 a b$ & $9,57 a$ & $2,22 a$ & $5,76 a$ & $28,46 a$ & $71,53 a$ & $3,35 a$ & $8,59 a$ \\
\hline CF & $1,18 \mathrm{c}$ & $5,70 a$ & $17,27 a$ & $82,72 a$ & $1,60 c$ & $7,70 a$ & $2,62 a$ & $5,93 a$ & $30,55 a$ & $69,45 a$ & $3,65 a$ & $8,23 a$ \\
\hline PP & $1,87 a$ & $6,23 a$ & $24,26 a$ & $75,73 a$ & $2,81 a$ & $9,35 a$ & \begin{tabular}{l}
$1,87 a$ \\
\hdashline
\end{tabular} & $5,32 a$ & $26,35 a$ & $73,64 a$ & $3,02 a$ & $8,54 a$ \\
\hline $\mathrm{CV}(\%)$ & 15,31 & 17,55 & 25,59 & 6,27 & 16,98 & 17,43 & 20,56 & 22,08 & 27,51 & 11,70 & 22,18 & 22,31 \\
\hline
\end{tabular}

Médias seguidas de mesma letra nas colunas para cada fragmento e camada, não diferem estatisticamente pelo teste Tukey (5\%). BO: Borda do fragmento; MR: Metade do raio; CF: Centro do fragmento; PP: Pastagem Permanente; CV (\%): coeficiente de variação.

Os teores de C-MOM apresentaram diferenças na camada 0-0,05 m entre os pontos avaliados em ambos fragmentos (Tabela 4), seguindo os mesmos padrões apresentados pelos resultados de COT (Figura 2), tendo o ponto $\mathrm{MR}, 20,22 \mathrm{~g} \mathrm{~kg}^{-1}$, com o maior teor no fragmento 1, e os pontos $\mathrm{CF}, 12,06 \mathrm{~g} \mathrm{~kg}^{-1}$, e BO, 8,09 $\mathrm{g} \mathrm{kg}^{-1}$, com os maiores teores no fragmento 2 (Tabela 4). Na camada 0,10-0,20 m, ambos os fragmentos não apresentaram diferenças entre os pontos avaliados, expressando variação de 5,70 a 7,14 $\mathrm{g} \mathrm{kg}^{-1}$ no fragmento 1 (Tabela 4) e de 5,32 a 6,02 entre os pontos no fragmento 2 (Tabela 4).

O C-MOM é formado pela decomposição do C-MOP e tende a ter maior representatividade em camadas subsuperficiais do perfil do solo (CHAN et al., 2001). O fato das áreas de PP apresentarem semelhanças nos teores de C-MOM com os pontos internos dos fragmentos de Cerrado, pode estar relacionado a liberação de material orgânico das raízes, por rizodeposição, consequentemente contribuindo para a formação de C-MOM (CARMO et al., 2012). Cardoso Junior et al. (2016) e Batista et al. (2013) também encontram semelhanças na fração de $C$ mais recalcitrante entre sistema de cultivo com pastagens e áreas nativas de Cerrado em camadas subsuperficiais do solo.

As porcentagens representativas de MOP e MOM não apresentaram diferenças acentuadas entre as mesmas com o aumento da profundidade, com diferenças apenas entre os pontos nas camadas 0-0,05 m do fragmento 1 e na camada 0,05-0,10 m do fragmento 2 (Tabela 4). De maneira geral, em todas as camadas estudadas, a representatividade percentual da MOP no fragmento 1 variou de 5,70 a 20,22\%, e da MOM de 67,72 a 84,83\%. Já no fragmento 2 essas representatividades variaram de 26,35 a 42,99\% para a MOP, e de 57,00 a 73,64\% para a MOM (Tabela 4). Isso sugere um melhor estado de conservação do fragmento 2 em 
relação ao fragmento 1.

A porcentagem de MOP chegando próximo a 50\% tem relação com a textura dos solos avaliados (CAMBARDELLA et al., 1992), e com aporte vegetal constante nos fragmentos de Cerrado (MALCHOW et al., 2017), que contribuem para maior representatividade desta fração, visto a tendência de se ter maior representatividade de MOM no perfil do solo. Galdos et al. (2009) estudando o estoque de carbono sob dois sistemas de manejo de solo, relataram que a representatividade de MOP do solo é dinâmica, e tem total influência do tipo de solo, o clima e do tipo/diversidade de material vegetal aportado sobre o solo. Batista et al. (2013) estudando sistemas com pastagens em Latossolo de Cerrado, obtiveram representatividade de MOM acima de $85 \%$ do COT em todos os sistemas avaliados e camadas.

Com relação aos Est. MOP e Est. MOM, não houveram diferenças entre os pontos, na maioria das camadas estudadas. O Est. MOP na camada 0-0,05 m do fragmento 1, e nas três camadas avaliadas do fragmento 2, não apresentaram diferenças entre os pontos. Nas camadas $0,05-0,10$ e 0,10-0,20 m do fragmento 1 , os maiores valores foram expressos na área de SPD, 1,91 Mg ha-1 e 2,81 Mg ha-1, respectivamente. Os resultados de Est. MOM de ambos os fragmentos só apresentou diferença na camada 0-0,05 m do fragmento 1 , tendo o maior valor no ponto MR $12,53 \mathrm{Mg} \mathrm{ha}^{-1}$. Os dados do presente trabalho contrastam com os apresentados por Carmo et al. (2012), que observaram redução de Est. MOP, e acréscimos de Est. MOM em sistema com pastagem no Cerrado, avaliando a camada 0-0,40 m. Batista et al. (2013) obtiveram valores de Est. MOP semelhantes a área de Cerradão, com aumento de Est. MOM em camadas mais profundas do solo.

O IEC do fragmento 1 apresentou o ponto MR o maior valor 1,47, com acréscimo de estoque comparado com a referência (CF) na camada 0-0,05, e a área de PP com o menor valor 0,74, indicando redução de estoque de carbono na camada 0-0,05 m quando comparado a referência (Tabela 5). Na camada 0,10-0,20 m do fragmento 1, os pontos BO, MR e a área de PP expressaram os maiores valores de IEC, 1,17; 1,29 e 1,17, respectivamente. No fragmento 2 , os pontos $B O$ e MR e a área de PP, apresentaram IEC na camada 0-0,05 m valores inferiores aos da referência, sendo que na camada 0,10-0,20 m, os pontos não diferiram (Tabela 5). Isso ressalta a contribuição das raízes de pastagens para o acúmulo de COT em camadas mais profundas do solo, mesmo em condição de manejo aquém da ideal (SANTOS et al., 2019), visto que em outros sistemas de plantio, dependendo do manejo adotado, podem comprometer o estoque de $\mathrm{C}$ do solo em camadas mais profundas (OLIVEIRA et al., 2016), aumentando emissões de $\mathrm{CO}_{2}$ para a atmosfera (LAL, 2018; SPEROW, 2018).

Os valores de $L$ ficaram abaixo de 1,0, indicando desequilíbrio entre a fração lábil e recalcitrante da MOS. A L não apresentou diferenças entre os pontos nas camadas 0,05-0,10 m e 0,10-0,20 m do fragmento 1, e nas camadas $0-0,05 \mathrm{~m}$ e 0,10-0,20 $\mathrm{m}$ do fragmento 2 (Tabela 5). Os pontos $\mathrm{CF}(0,48)$, BO $(0,33)$ e PP $(0,35)$ apresentaram maiores valores de $L$ na camada 0-0,05 m do fragmento 1 . Já no fragmento 2, na camada 0,050,10 m, o ponto MR apresentou o maior valor, 0,76 (Tabela 5).

Briedis et al. (2018) relatam a importância do equilíbrio entre frações lábeis e recalcitrantes, principalmente pelo papel que cada uma desempenha no sistema. A fração lábil para formação e 
manutenção de macroagregados, que protege a MOS. E a fração recalcitrante, para formação de microagregados e aumento de estoque de carbono em camadas subsuperficiais do solo. Cardoso Junior et al. (2016) estudando diferentes sistemas de pastagens comparados a áreas de Cerrado nativo, obtiveram maiores valores de $L$ nas áreas com pastagens em dois períodos distintos do ano. Maior $L$ em áreas com pastagens comparados a Cerrado nativo foram também verificados por Oliveira et al. (2016).

Tabela 5: Índice de estoque de carbono (IEC), labilidade da MOS (L), índice de labilidade (IL) e índice de manejo do carbono (IMC) dos diferentes pontos de coleta no interior e ao entorno dos fragmentos 1 e 2 do bioma Cerrado.

\begin{tabular}{|c|c|c|c|c|c|c|c|c|}
\hline & \multicolumn{4}{|c|}{ Fragmento 1} & \multicolumn{4}{|c|}{ Fragmento 2} \\
\hline & IEC & $\mathrm{L}$ & $\mathrm{IL}$ & IMC & IEC & $\mathrm{L}$ & $\mathrm{IL}$ & IMC \\
\hline \multicolumn{9}{|c|}{$0-0,05 \mathrm{~m}$} \\
\hline BO & $1,01 b$ & $0,33 a b$ & $0,69 a b$ & $70,60 a b$ & $0,75 b$ & $0,68 a$ & $1,39 a$ & $105,73 a$ \\
\hline MR & $1,47 a$ & $0,18 b$ & $0,42 b$ & $59,26 b$ & $0,74 b$ & $0,66 a$ & $1,37 a$ & $100,20 a$ \\
\hline CF & $1,00 \mathrm{~b}$ & $0,48 a$ & $1,00 a$ & $100,00 a$ & $1,00 a$ & $0,49 a$ & $1,00 a$ & $100,00 a$ \\
\hline PP & $0,74 c$ & $0,35 a b$ & $0,72 a b$ & $53,78 b$ & $0,73 b$ & $0,49 a$ & $1,07 a$ & $73,65 a$ \\
\hline $\mathrm{CV}(\%)$ & 10,23 & 32,22 & 21,88 & 23,36 & 10,40 & 31,14 & 17,25 & 17,18 \\
\hline \multicolumn{9}{|c|}{$0,05-0,10 \mathrm{~m}$} \\
\hline $\mathrm{BO}$ & $1,27 a$ & $0,19 a$ & $0,75 a$ & $88,61 a$ & $0,98 a$ & $0,51 a b$ & $1,17 a b$ & $113,14 a b$ \\
\hline$M R$ & $1,27 a$ & $0,24 a$ & $0,84 a$ & $103,17 a$ & $0,72 b$ & $0,76 a$ & $1,71 a$ & $124,54 a$ \\
\hline CF & $1,00 a$ & $0,33 a$ & $1,00 a$ & $100,00 a$ & $1,00 a$ & $0,45 b$ & $1,00 a b$ & $100,00 a b$ \\
\hline PP & $0,99 a$ & $0,39 a$ & $1,32 a$ & $130,21 a$ & $0,76 b$ & $0,40 \mathrm{~b}$ & $0,90 \mathrm{~b}$ & $68,21 \mathrm{~b}$ \\
\hline $\mathrm{CV}(\%)$ & 13,92 & 34,34 & 42,90 & 37,53 & 7,39 & 24,20 & 30,27 & 25,27 \\
\hline \multicolumn{9}{|c|}{$0,10-0,20 \mathrm{~m}$} \\
\hline $\mathrm{BO}$ & $1,14 a b$ & $0,20 a$ & $0,97 a$ & $112,14 b$ & $1,05 a$ & $0,54 a$ & $1,22 a$ & $121,27 a$ \\
\hline MR & $1,29 a$ & $0,25 a$ & $1,22 a$ & $157,59 a b$ & $0,93 a$ & $0,41 a$ & $0,94 a$ & $86,26 a$ \\
\hline CF & $1,00 b$ & $0,20 a$ & $1,00 a$ & $100,00 b$ & $1,00 a$ & $0,44 a$ & $1,00 a$ & $100,00 a$ \\
\hline PP & $1,17 a b$ & $0,33 a$ & $1,59 a$ & $175,70 a$ & $0,84 a$ & $0,37 a$ & $0,84 a$ & $70,48 a$ \\
\hline $\mathrm{CV}(\%)$ & 11,30 & 36,50 & 33,94 & 22,17 & 14,00 & 39,47 & 38,82 & 30,03 \\
\hline
\end{tabular}

Médias seguidas de mesma letra nas colunas para cada fragmento e camada, não diferem estatisticamente pelo teste Tukey (5\%). BO: Borda do fragmento; MR: Metade do raio; CF: Centro do fragmento; PP: Pastagem Permanente; CV (\%): coeficiente de variação.

Os valores de IL expressaram o mesmo padrão da L, não apresentando diferenças entre os pontos na maioria das camadas avaliadas (Tabela 5). Cardoso Junior et al. (2016) também obtiveram resultados de IL semelhantes entre sistemas com pastagens e Cerrado nativo. Os valores de IMC demostraram comportamento distinto entre os fragmentos 1 e 2 . Na camada 0-0,05 m do fragmento 1 , o ponto $\mathrm{BO}$ se assemelhou ao ponto de referência (CF), com maiores valores (Tabela 5). Na camada 0,05-0,10 m do fragmento 1, não houveram diferenças entre os pontos internos e a área de PP ao entorno, sendo que na camada de 0,10-0,20 m, a área de PP 175,70 e o ponto MR 157,59 apresentaram os maiores valores (Tabela 5).

Os valores de IMC apresentados pela área de PP na camada 0,10-0,20 m especialmente no fragmento 1 mostra a contribuição dos teores de COT apresentados pelas áreas de PP avaliadas no Cerrado (Figura 2) e que condizem com a conclusão de Sales et al. (2017), de que sistemas que utilizam de espécies de pastagens são promissores no acúmulo e manutenção do carbono orgânico, principalmente em camadas subsuperficiais do solo. Gazolla et al. (2015) obtiveram valor de IMC 97,36 em área de pastagem permanente na camada 0,2-0,4 m, valor muito próximo da referência. Cardoso Junior et al. (2016) relataram valores de IMC de 147,5 e 129,5 para sistema com Brachiaria brizantha e Panicum maximum, respectivamente.

No fragmento 2, os resultados de IMC não apresentaram diferenças entre os pontos avaliados nas 
camadas $0-0,05$ e 0,10-0,20 m, sendo que na camada 0,05-0,10 m o ponto MR apresentou maior valor, superando o ponto referência (Tabela 5). Santos et al. (2017) encontraram valores de IMC de 49,3 em pastagens cultivadas na região sudoeste do estado de Mato Grosso. Valores de IMC acima de 120 em áreas com pastagens também foram encontrados por Oliveira et al. (2016). Bayer et al. (2004) relatam a importância do aporte continuo de material vegetal no solo para se manter os processos edáficos, e que a interferência neste processo pode comprometer a qualidade da MOS, tornando o IMC importante ferramenta de avaliação de qualidade do carbono do solo, visto que a variável relaciona frações lábeis e recalcitrantes da MOS.

As maiores emissões iniciais de $\mathrm{C}-\mathrm{CO}_{2}$ no fragmento 1 foram observadas nos pontos $\mathrm{BO}$ e CF (Figura 3a), sendo 4,85 e 3,35 mg de C- $\mathrm{CO}_{2}$ em $50 \mathrm{~g}$ de solo no 1 o dia, e 6,27 e 5,36 mg de $\mathrm{C}-\mathrm{CO}_{2}$ em $50 \mathrm{~g}$ de solo no 2 ㅇ dia, respectivamente. No fragmento 2 , no primeiro dia de avaliação, a maior emissão ocorreu nos pontos $\mathrm{BO}$ e MR de forma semelhante, 6,24 mg de $\mathrm{C}-\mathrm{CO}_{2}$ em $50 \mathrm{~g}$ de solo (Figura 3b). Esses dados confirmam que as maiores emissões iniciais ocorreram nos pontos onde se teve também maiores teores de COT (Figura 2) e CMOP (Tabela 4).

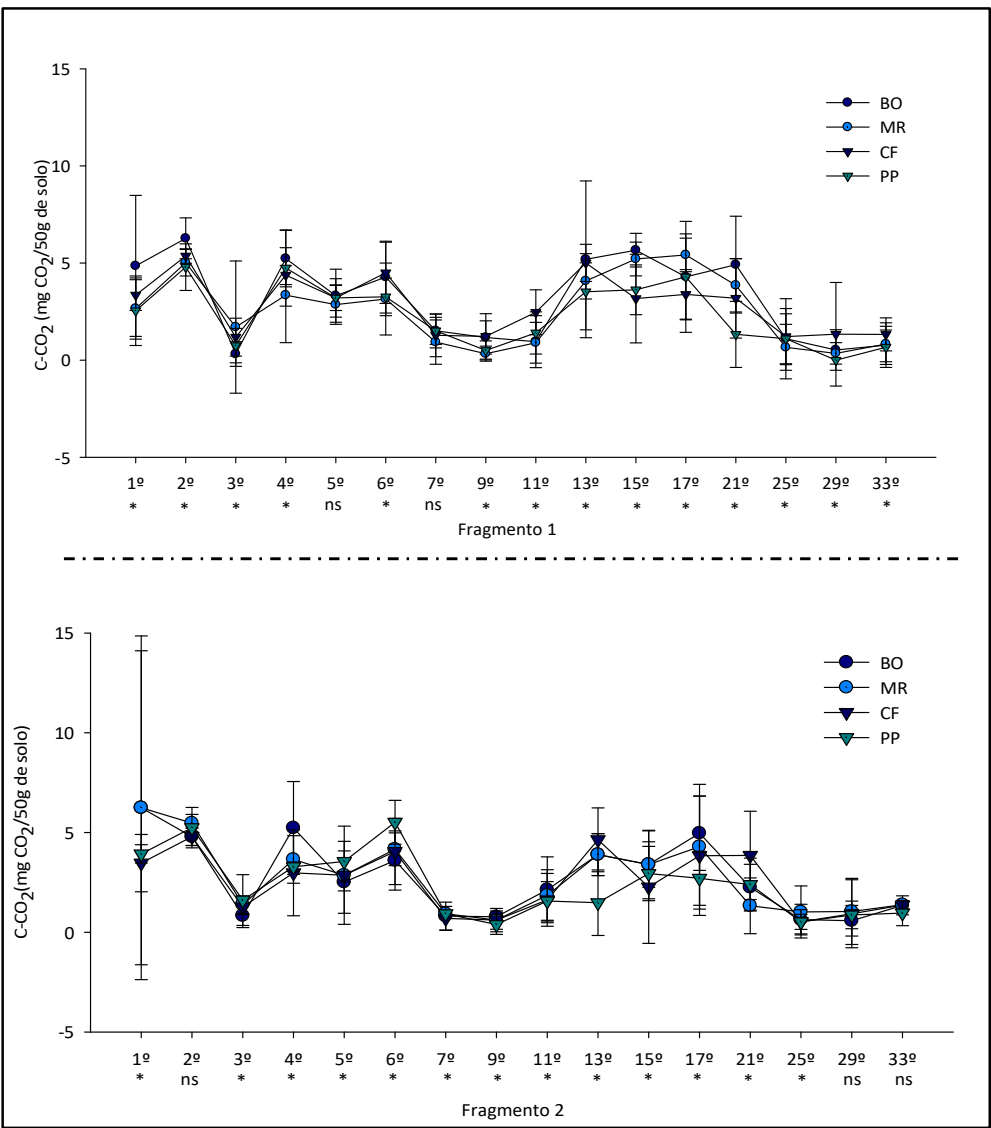

Figura 3: Carbono mineralizável do solo incubado em laboratório até o 33ㅇ dia, dos diferentes pontos de coleta no interior e ao entorno dos fragmentos 1 (a) e 2 (b) do bioma Cerrado. * = Significativo pelo teste de Tukey a 5\%; n/s = Não significativo pelo teste de Tukey a $5 \%$.

Em ambos os fragmentos, os pontos avaliados apresentaram entre o 4ㅇ e 60 e entre 13 e 21으 dias de avaliação picos de emissão (Figuras $3 \mathrm{a}, \mathrm{b}$ ). Queda mesma forma como nos primeiros dias, os pontos que apresentam os maiores picos de emissão, foram aqueles que contêm os maiores teores de carbono lábil (Tabela 4), que estimula a atividade dos microrganismos (KUZYAKOV et al., 2000; HURISSO et al., 2018), 
gerando emissão de $\mathrm{C}_{-} \mathrm{CO}_{2}$. A partir do 25 ㅇ dia para os fragmentos 1 e 2, houve estabilização na emissão C$\mathrm{CO}_{2}$, devido provavelmente pela diminuição de materiais orgânicos lábeis prontamente disponíveis ao ataque microbiano.

No fragmento 1 , o ponto $\mathrm{BO}$ apresentou maior acúmulo de emissão de $\mathrm{C}-\mathrm{CO}_{2}$, seguido dos pontos $\mathrm{CF}$ e MR, 49,10; 45,57; 41,29 mg C- $\mathrm{CO}_{2}$ em $50 \mathrm{~g}$ de solo, respectivamente (Figura 4). A área de PP ao entorno do fragmento 1 apresentou o menor acúmulo de emissão, 37,26 mg C- $\mathrm{CO}_{2}$ em $50 \mathrm{~g}$ de solo (Figura 4), o equivalente a $24,20 \%$ menos emissão comparado ao ponto BO.

No fragmento 2, os pontos BO e MR apresentaram os maiores valores de acúmulo de emissão, 44,51 e 43,48 mg C- $\mathrm{CO}_{2}$ em $50 \mathrm{~g}$ de solo respectivamente, e a área de PP ao entorno também o menor valor de acúmulo de emissão, 37,65 mg C- $\mathrm{CO}_{2}$ em $50 \mathrm{~g}$ de solo (Figura 4), apresentando redução de emissão de 15,42\% e 13,41\% em relação aos pontos BO e MR, respectivamente. $O$ fato de os pontos internos dos fragmentos apresentarem maiores emissões, ocorre principalmente pelo maior aporte de serapilheira nessas áreas, principalmente pela relação do $\mathrm{C}$ nas formas mais lábeis na camada mais superficial, com a emissão de $\mathrm{C}-\mathrm{CO}_{2}$ (BORGES et al., 2015).

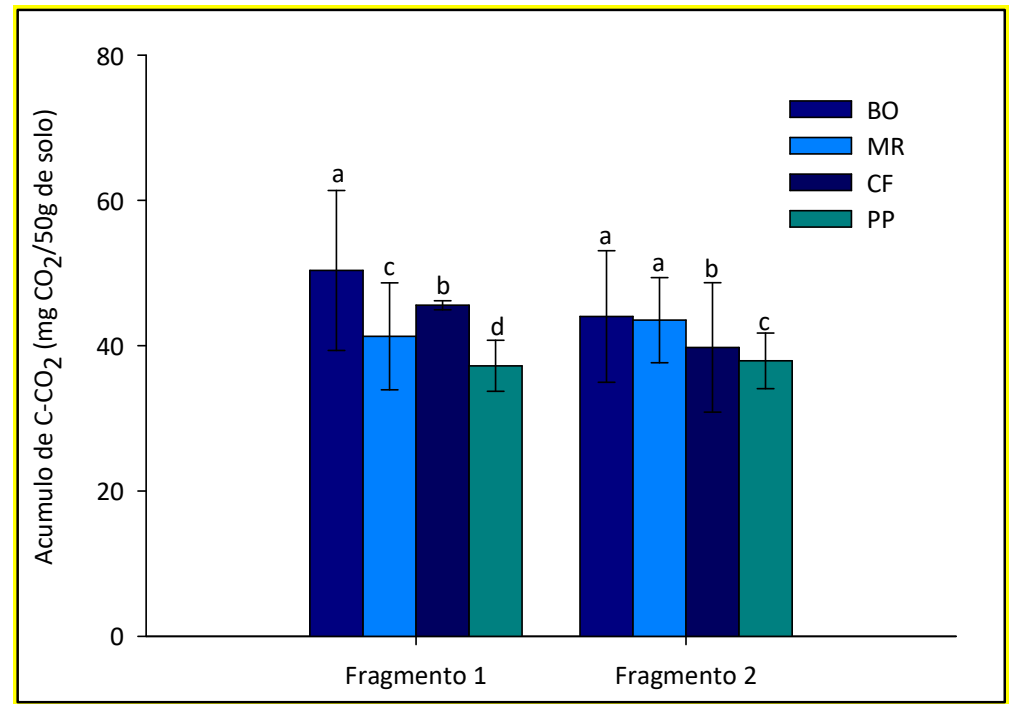

Figura 4: Acúmulo de $\mathrm{C}_{-} \mathrm{CO}_{2}$ ( $\mathrm{mg} \mathrm{CO} / 50 \mathrm{~g}$ de solo), durante o período de incubação do solo em laboratório nos diferentes pontos de coleta no interior e ao entorno dos fragmentos 1 e 2 do bioma Cerrado. *Médias de mesma letra, não diferem estatisticamente pelo teste Tukey (5\%). BO: Borda do fragmento; MR: Metade do raio; CF: Centro do fragmento; PP: Pastagem permanente; Traços nas barras representam o desvio padrão dos dados.

O baixo acúmulo de emissão de $\mathrm{C}-\mathrm{CO}_{2}$ apresentado pelas áreas de PP, pode estar relacionado com a baixa heterogeneidade vegetal depositada, uma vez que áreas de Cerrado apresentam serapilheira diversificada, com diferentes estratos florestais (BARBOSA et al., 2017). Loss et al. (2013) após 37 dias de incubação, obtiveram acúmulo semelhante entre pastagens e área de Cerradão. Borges et al. (2015) também obtiveram resultados de emissão de $\mathrm{C}-\mathrm{CO}_{2}$ semelhantes entre áreas de pastagens e Cerrado. Dados esses, contrastantes com a diferença de emissão entre as áreas de Cerrado e PP deste estudo.

\section{CONCLUSÕES}

Em ambos os fragmentos as áreas de pastagem apresentaram o mesmo potencial de acúmulo de 
carbono que os pontos no interior dos fragmentos na camada 0,10-0,20. 0 carbono da matéria orgânica particulada apresentou comportamento distinto entre os fragmentos, sendo que para ambos, o carbono da matéria orgânica mineral prevaleceu em relação ao carbono da matéria orgânica particulada. A conversão de áreas nativas do Cerrado em áreas de pastagens não influenciou no índice de manejo de carbono. As conversões de áreas nativas de Cerrado em áreas de pastagens permanentes comprometeram a atividade microbiana, ocasionando menores acúmulos de emissão de $\mathrm{C}-\mathrm{CO}_{2}$.

AGRADECIMENTOS: Agradecemos a Coordenação de Aperfeiçoamento de Pessoal de Nível Superior (CAPES) pela concessão da bolsa de mestrado ao primeiro autor, à Universidade Estadual de Mato Grosso do Sul e aos proprietários rurais que autorizaram o desenvolvimento deste estudo em suas áreas.

\section{REFERÊNCIAS}

AZIZ, I.; MAHMOOD, T.; ISLAM, K. R.. Effect of long term notill and conventional tillage practices on soil quality. Soil \& Tillage Research, v.131, p.28-35, 2013. DoI: https://doi.org/10.1016/j.still.2013.03.002

ASSUNÇÃO, S. A.; PEREIRA, M. G.; ROSSET, J. S.; BERBARA, R. L. L.; GARCÍA, A. C.. Carbon input and the structural quality of soil organic matter as a function of agriculturalmanagement in a tropical climate region of Brazil. Science of the Total Environment, v.658, p.901-911, 2019. DOI: https://doi.org/10.1016/j.scitotenv.2018.12.271

BALDOTTO M. A.; CANELA, M. C.; CANELLAS, L. P.; DOBBSS, L. B.; VELLOSO, A. C. X.. Redox índex of soil carbon stability. Revista Brasileira de Ciência do Solo, v.34, n.5, p.1543-1551, 2010. DOI: http://dx.doi.org/10.1590/S010006832010000500007

BARBOSA, E. A. A.; MATSURA, E. E.; SANTOS, L. N. S.; NAZÁRIO, A. A.; GONÇALVES, I. Z.; FEITOSA, D. R. C.. Soil attributes and quality under treated domestic sewage irrigation in sugarcane. Revista Brasileira de Engenharia Agrícola e Ambiental, v.22, n.2, p.137-142, 2018. DOI: http://dx.doi.org/10.1590/1807-1929/agriambi.v22n2p137$\underline{142}$

BARBOSA, V.; GARCIA, P. B.; RODRIGUES, E. G.; PAULA, A.. Biomassa, carbono e nitrogênio na serapilheira acumulada de florestas plantadas e nativa. Floresta e Ambiente, v.24, p.1-9, 2017. DOI: http://dx.doi.org/10.1590/21798087.025116

BARROS, H. S.; FEARNSIDE, P. M.. Soil carbon stock changes due to edge effects in central Amazon forest fragments. Forest Ecology and Management, v.379, p.30-36, 2016. DOI: https://doi.org/10.1016/j.foreco.2016.08.002

BATISTA, I.; PEREIRA, M. G.; CORREIA, M. E. F.; BIELUCZYK, W.; SCHIAVO, J. A.; ROWS, C.; RIBEIRO, J.. Teores e estoque de carbono em frações lábeis e recalcitrantes da matéria orgânica do solo sob integração lavoura-pecuária no bioma Cerrado. Semina: Ciências Agrárias, v.34, n.6, p.3377-3388, 2013. DOI:

http://www.redalyc.org/articulo.oa?id=445744137022

BAYER, C.; MARTIN NETO, L.; MIELNICZUK, J.; PAVINATO,
A.. Armazenamento de carbono em frações lábeis da matéria orgânica de um Latossolo Vermelho sob plantio direto. Pesquisa Agropecuária Brasileira, v.39, n.7, p.677683, 2004. DOI: http://dx.doi.org/10.1590/S0100204X2004000700009

BLAIR, G. J.; LEFROY, R. D. B.; LISLE, L.. Soil carbon fractions based on their degree of oxidation, and the development of a carbon management index for agricultural systems. Australian Journal of Agricultural Research, v.46, n.7, p.1459-1466, 1995. DOI: https://doi.org/10.1071/AR9951459

BORGES, S. C.; RIBEIRO, B. T.; WENDLING, B.; CABRAL, D. A. Agregação do solo, carbono orgânico e emissão de $\mathrm{CO}_{2}$ em áreas sob diferentes usos no Cerrado, região do Triângulo Mineiro. Revista Ambiente \& Água, v.10, n.3, p.661-675, 2015. DOI: http://dx.doi.org/10.4136/ambi-agua.1573.

BRIEDIS, C.; SÁ, J. C. M.; LAL, R.; TIVET, F.; FRANCHINI, J. C.; FERREIRA, A. O.; ROMANIW, J.. How does no-till deliver carbon stabilization and saturation in highly weathered soils? Catena, v.163, p.13-23, 2018. DOI: https://doi.org/10.1016/i.catena.2017.12.003

CAMBARDELLA, C. A.; ELLIOTT, E. T.. Particulate soil organicmatter changes across a grassland cultivation sequence. Soil Science Society of America Journal, v.56, n.3, p.777-783, 1992. DOI: https://doi.org/10.2136/sssaj1992.03615995005600030017 $\underline{x}$

CARDOZO JUNIOR, F. M.; CARNEIRO, R. F. V.; LEITE, L. F. C.; ARAUJO, A. S. F.. Soil carbon pools in different pasture systems. Spanish Journal of Agricultural Research, v.14, p 15, 2016. DOI: http://dx.doi.org/10.5424/sjar/2016141-7939

CARMO, F. F.; FIGUEIREDO, C. C.; RAMOS, M. L. G.; VIVALDI, L. J.; ARAÚJO, L. G.. Frações granulométricas da matéria orgânica em Latossolo sob plantio direto com gramíneas. Bioscience Journal, v.28, p.420-431, 2012.

CARVALHO, M. A. C.; PANOSSO, A. R.; TEIXEIRA, E. E. R.; ARAÚJO, E. G.; BRANCAGLIONI, V. A.; DALLACORT, R.. Multivariate approach of soil attributes on the characterization of land use in the southern Brazilian 
Amazon. Soil \& Tillage Research, v.184, p.207-215, 2018. DOI: https://doi.org/10.1016/i.still.2018.08.004

CHAN, K. Y.; BOWMAN, A.; OATES, A.. Oxidizidable organic carbon fractions and soil quality changes in an oxic paleustalf under different pasture ley. Soil Science, v.166, p.61-67, 2001.

CLAESSEN, M. E. C.. Manual de métodos de análise de solo. 2 ed. Rio de Janeiro: Embrapa, 1997.

DALMOLIN, R. S. D.; CATEN, A. T.. Uso da terra dos biomas brasileiros e o impacto sobre a qualidade do solo. EntreLugar, v.3, n.6, p.181-193, 2012.

DIDHAM, R. K.. Altered leaf-litter decomposition rates in tropical forest fragments. Oecologia, v.116, n.3, p.397-406, 1998. DOI: https://doi.org/10.1007/s004420050603

DORAN, J. W.; PARKIN, T. B.. Defining and assessing soil quality. In: DORAN, J. W.; COLEMAN, D. C.; BEZDICEK, D. F.; STEWART, B. A.. Defining soil quality for a sustainable environment. Madison: Soil Science Society of America, 1994. p.3-22

FERREIRA, A. O.; SÁ, J. C. M; LAL, R.; TIVET, F.; BRIEDIS, C.; INAGAKI, T. M.; ROMANIW, J.. Macroaggregation and soil organic carbon restoration in a highly weathered Brazilian Oxisol after two decades under no-till. Science of the Total Environment, v.621, p.1559-1567, 2018. DOI: https://doi.org/10.1016/j.scitotenv.2017.10.072

FERREIRA, C. R.; SILVA NETO, E. C.; PEREIRA, M. G.; GUEDES, J. N.; ROSSET, J. S.; ANJOS, L. H. C.. Dynamics of soil aggregation and organic carbon fractions over 23 years of no-till management. Soil \& Tillage Research, v.198, p.1-9 (104533), 2020. Dol: https://doi.org/10.1016/i.still.2019.104533.

FERREIRA, E. B.; CAVALCANTI, P. P.; NOGUEIRA, D. A.. ExpDes.pt: Pacote Experimental Designs (Portuguese). $\mathrm{R}$ package version 1.2.0. 2018.

GALDOS, M. V.; CERRI, C. C.; CERRI, C. E. P.. Soil carbon stocks under burned and unburned sugarcane in Brazil. Geoderma, v.153, p.347-352, 2009. DOI: https://doi.org/10.1016/j.geoderma.2009.08.025

GAZOLLA, P. R.; GUARESCHI, R. F.; PERIN, A.; PEREIRA, M. G.; ROSSI, C. Q.. Frações da matéria orgânica do solo sob pastagem, sistema plantio direto e integração lavourapecuária. Semina: Ciências Agrárias, v.36, n.2, p.693-704, 2015. DOI:

http://www.redalyc.org/articulo.oa?id=445744147010

GMACH, M. R.; DIAS, B. O.; SILVA, C. A.; NÓBREGA, J. C.; LUSTOSA-FILHO, J. F.; SIQUEIRA-NETO, M.. Soil organic matter dynamics and land-use change on Oxisols in the Cerrado, Brazil. Geoderma Regional, v.14, p.1-8, 2018. DOI: https://doi.org/10.1016/j.geodrs.2018.e00178

GUIMARÃES, D. V.; GONZAGA, M. I. S.; MELO NETO, J. O.; REIS, A. F.; LIMA, T. S.; SANTANA, I. L.. Qualidade da matéria orgânica do solo e estoques de carbono e nitrogênio em fragmento de Mata Atlântica do Município de Neópolis, Sergipe. Scientia Plena, v.8, p.1-5, 2012.
HURISSO, T. T.; CULMAN, S. W.; ZONE, P.; SHARMA, S.. Absolute values and precision of emerging soil health indicators as affected by soil sieve size. Communications in Soil Science and Plant Analysis, v.49, n.15, p.1934-1942, 2018. DOI: https://doi.org/10.1080/00103624.2018.1492597

KOVEN, C. D.; HUGELIUS, G.; LAWRENCE, D. M.; WIEDER, W. R.. Higher climatological temperature sensitivity of soil carbon in cold than warm climates. Nature Climate Change, v.7, n.11, p.817, 2017. DOI: https://doi.org/10.1038/nclimate3421

KUZYAKOV, Y.; FRIEDEL, J. K.; STAHR, K.. Review of mechanisms and quantification of priming effects. Soil Biology and Biochemistry, v.32, n.11-12, p.1485-1498, 2000. DOI: https://doi.org/10.1016/S0038-0717(00)00084-5

LAL, R.. Digging deeper: A holistic perspective of factors affecting soil organic carbon sequestration in agroecosystems. Global Change Biology, v.24, p.3285-3301, 2018. DOI: https://doi.org/10.1111/gcb.14054

LIANG, A.; ZHANG, Y.; ZHANG, X.; YANG, X.; MCLAUGHLIN, N.; CHEN, X.; TANG, J.. Investigations of relationships among aggregate pore structure, microbial biomass, and soil organic carbon in a Mollisol using combined non-destructive measurements and phospholipid fatty acid analysis. Soil \& Tillage Research, v.185, p.94-101, 2019. DOI: https://doi.org/10.1016/i.still.2018.09.003

LOSS, A.; BASSO, A.; OLIVEIRA, B. S.; KOUCHER, L. P.; OLIVEIRA, R. A.; KURTZ, C.; COMIN, J. J.. Carbono orgânico total e agregação do solo em sistema de plantio direto agroecológico e convencional de cebola. Revista Brasileira de Ciência do Solo, v.39, n.4, p.1212-1224, 2015. DOI: http://dx.doi.org/10.1590/01000683rbcs20140718

LOSS, A.; PEREIRA, M. G.; BEUTLER, S. J.; PERIN, A.; ANJOS, L. H. C.. Carbono mineralizável, carbono orgânico e nitrogênio em macroagregados de Latossolo sob diferentes sistemas de uso do solo no Cerrado Goiano. Semina: Ciências Agrárias, v.34, n.5, p.2153-2168, 2013. DOI:

http://www.redalyc.org/articulo.oa? id=445744135013

MAGALHÃES, S. S. A.; RAMOS, F. T.; WEBER, O. L. S.. Carbon stocks of an Oxisol after thirty-eight years under different tillage systems. Revista Brasileira de Engenharia Agrícola e Ambiental, v.20, n.1, p.85-91, 2016. Dol: http://dx.doi.org/10.1590/1807-1929/agriambi.v20n1p85$\underline{91}$

MALCHOW, E.; KOEHLER, A. B.; NETTO, S. P.. Efeito de borda em um trecho da floresta ombrófila mista, em fazenda Rio Grande, PR. Revista Acadêmica: Ciência Animal, v.4, n.2, p.85-95, 2017.

MALHEIROS, R.. Influência da sazonalidade na dinâmica da vida no bioma cerrado. Revista Brasileira de Climatologia, v.19, p.113-128, 2016. DOI: http://dx.doi.org/10.5380/abclima.v19i0.48876

MARQUES, J. D. O.; LUIZÃO, F. J.; TEIXEIRA, W. G.; SARRAZIN, M.; FERREIRA, S. J. F.; BELDINI, T. P.; MARQUES, E. M. A.. Distribution of organic carbon in different soil fractions in ecosystems of central Amazônia. Revista Brasileira de 
Ciência do Solo, v.39, n.1, p.232-242, 2015. DOI: http://dx.doi.org/10.1590/01000683rbcs20150142

MENDONÇA, E. S.; MATOS, E. S.. Matéria orgânica do solo: métodos de análises. Ponte Nova: D \& M Ltda., 2005.

NOVAIS, D. B.; FERREIRA, J. S.; BARRETO, P. A. B.. Fertilidade do solo como indicador do efeito de borda em fragmento florestal, Vitória da Conquista, Bahia. Revista Verde de Agroecologia e Desenvolvimento Sustentável, v.11, n.4, p.185-189, 2016. DOI: https://doi.org/10.18378/rvads.v11i4.4081

OBOUR, P. B.; JENSEN, J. L.; LAMANDÉ, M.; WATTS, C. W.; MUNKHOLM, L. J.. Soil organic matter widens the range of water contents for tillage. Soil \& Tillage Research, v.182, p.57-65, 2018. DOI: https://doi.org/10.1016/i.still.2018.05.001

OLIVEIRA, D. M. S.; LIMA, R. P.; BARRETO, M. S. C.; VERBURG, E. E. J.; MAYRINK, G. C. V.. Soil organic matter and nutrient accumulation in areas under intensive management and swine manure application. Journal of Soils and Sediments, v.17, n.1, p.1-10, 2016. DOI: https://doi.org/10.1007/s11368-016-1474-6

OLIVEIRA, L. S. C.; MARANGON, L. C.; FELICIANO, A. L. P.; LIMA, A. S.; CARDOSO, M. S. O.; SANTOS, W. B.; CARDOSO, L. S.. Efeito de borda em remanescentes de floresta atlântica na bacia do rio Tapacurá, Pernambuco. Cerne, v.21, n.2, p.169-174, 2015. DOI: http://dx.doi.org/10.1590/01047760201521021185

PINTO JUNIOR, O. B.; CARVALHO, P. V.; COUTO, E. G.. Study of $\mathrm{CO} 2$ flux and soil carbon in northern Pantanal, Brazil. Revista Ibero-Americana de Ciências Ambientais, v.9 n.5, p.29-38, 2018. DOI: http://doi.org/10.6008/CBPC2179$\underline{6858.2018 .005 .0004}$

R CORE TEAM. R: A language and environment for statistical computing. Vienna: R Foundation for Statistical Computing, 2019.

RAMOS, F. T.; DORES, E. F. D. C.; WEBER, O. L. D. S.; BEBER, D. C.; CAMPELO JUNIOR, J. H.; MAIA, J. C. D. S.. Soil organic matter doubles the cation exchange capacity of tropical soil under no-till farming in Brazil. Journal of the Science of Food and Agriculture, v.98, p.3595-3602, 2018. DOI: https://doi.org/10.1002/jsfa.8881

RANGEL, O. J. P.; SILVA, C. A.. Estoques de carbono e nitrogênio e frações orgânicas de Latossolo submetido a diferentes sistemas de uso e manejo. Revista Brasileira de Ciência do Solo, v.31, p.1609-1623, 2007. DOI: http://dx.doi.org/10.1590/S0100-06832007000600037

REIS, D. A.; PORTELLA, R. B.; FAGUNDES, M. O.; JÚNIOR, F. R F.; SANTOS, J. R. S., BOGIANI, J. C.; PERINA, F. J.. Grau de dispersão, biomassa microbiana e carbono orgânico de um latossolo cultivado com soja sob plantio convencional e direto no cerrado (savana) do oeste da Bahia, Brasil. Revista Ibero-Americana de Ciências Ambientais, v.10, n.1, p.363375, 2019. DOI: https://doi.org/10.6008/CBPC2179$\underline{6858.2019 .001 .0030}$

REIS, V. R. R.; DEON, D. S.; MUNIZ, L. C.; SILVA, M. B.; REGO, C. A. R. M.; GARCIA, U. C.; CANTANHÊDE, I. S. L.; COSTA, J. B..
Carbon Stocks and Soil Organic Matter Quality Under Different of Land Uses in the Maranhense Amazon. Journal of Agricultural Science, v.10, n.5, p.329, 2018. DOI: http://doi.org/10.5539/jas.v10n5p329

RESENDE, T. M.; ROSOLEN, V.; BERNOUX, M.; BRITO, J. L. S.; NASCENTES BORGES, E.; ALMEIDA, F. P.. Atributos físicos e carbono orgânico em solo sob cerrado convertido para pastagem e sistema misto. Sociedade \& Natureza, v.27, n.3, p.500-513, 2015. DOI: http://dx.doi.org/10.1590/1982451320150310 .

ROMANIW, J.; SÁ, J. C. M.; PADILHA, A. A.; RAMOS, F. S.; EURICH, G.; BRESSAN, P. T.. Carbon dynamics in no-till soil due to the use of industrial organic waste and mineral fertilizer. Revista Ciência Agronômica, v.46, n.3, p.477-487, 2015. DOI: http://dx.doi.org/10.5935/1806-6690.20150029

ROSSET, J. S.; LANA, M. C.; PEREIRA, M. G.; SCHIAVO, J. A.; RAMPIM, L.; SARTO, M. V. M.; SEIDEL, E. P.. Estoque de carbono, propriedades químicas e físicas do solo em sistemas de manejo com diferentes tempos de implantação na Região Oeste do Paraná, Brasil. Semina: Ciências Agrárias, v.35, n.6, p.3053-3072, 2014. DOI: http://doi.org/10.5433/1679-0359.2014v35n6p3053

ROSSET, J. S.; LANA, M. C; PEREIRA, M. G.; SCHIAVO, J. A.; RAMPIM, L.; SARTO, M. V. M.. Frações químicas e oxidáveis da matéria orgânica do solo sob diferentes sistemas de manejo, em Latossolo Vermelho. Pesquisa Agropecuária Brasileira, v.51, n.9, p.1529-1538, 2016. DOI: http://dx.doi.org/10.1590/s0100-204x2016000900052

ROSSET, J. S.; LANA, M. C.; PEREIRA, M. G.; SCHIAVO, J. A.; RAMPIM, L.; SARTO, M. V. M.. Organic matter and soil aggregation in agricultural systems with different adoption times. Semina: Ciências Agrárias, v.40, n.6, p.3443-3460, 2019. DOI: http://doi.org/10.5433/16790359.2019v40n6Supl3p3443

SALES, A.; SILVA, A. R.; VELOSO, C. A. C.; CARVALHO, E. J. M.; MIRANDA, B. M.. Carbono orgânico e atributos físicos do solo sob manejo agropecuário sustentável na Amazônia Legal. Colloquium Agrariae, v.14, n.1, p.1-15, 2018. DOI: http://doi.org/10.5747/ca.2018.v14.n1.a185

SALES, R. P.; PEGORARO, R.; PORTUGAL, A. F.; MOREIRA, J. A. A.; KONDO, M. K.. Organic matter fractions of an irrigated oxisol under no-till and conventional tillage in the Brazilian semi-arid region. Revista Caatinga, v.30, n.2, p.303-312, 2017. DOI: http://dx.doi.org/10.1590/198321252017v30n205rc.

SALTON, J.C.; MIELNICZUK, J.; BAYER, C.; BOENI, M.; CONCEIÇÃO, P. C.; FABRÍCIO, A. C.; MACEDO, M. C. M.; $B R O C H, D$. L.. Agregação e estabilidade de agregados do solo em sistemas agropecuários em Mato Grosso do Sul. Revista Brasileira de Ciência do Solo, v.32, n.1, p.11-21, 2008. DOI: http://dx.doi.org/10.1590/S0100-06832008000100002

SANTOS, C. A.; REZENDE, C. D. P.; PINHEIRO, É. F. M.; PEREIRA, J. M.; ALVES, B. J.; URQUIAGA, S.; BODDEY, R. $M$.. Changes in soil carbon stocks after land-use change from native vegetation to pastures in the Atlantic forest region of Brazil. Geoderma, v.337, p.394-401, 2019. DOI: https://doi.org/10.1016/j.geoderma.2018.09.045 
SANTOS, F. A. S.; PIERANGELI, M. A. P.; SILVA, F. L.; SERAFIM, M. E.; SOUSA, J. B.; OLIVEIRA, E. B.. Dinâmica do carbono orgânico de solos sob pastagens em campos de murundus. Scientia Agraria, v.18, n.2, p.43-53, 2017. DOI: http://www.redalyc.org/articulo.oa?id=99551919005

SANTOS, H. G.; JACOMINE, P. K. T.; ANJOS, L. H. C.; OLIVEIRA, V. A.; LUMBRERAS, J. F.; COELHO, M. R.; ALMEIDA, J. A.; CUNHA, T. J. F.; OLIVEIRA, J. B.. Sistema Brasileiro de Classificação de Solos. 3 ed. Brasília: Embrapa, 2013.

SAUNDERS, D. A.; HOBBS, R. J.; MARGULES, C. R.. Biological consequences of ecosystem fragmentation: a review. Conservation Biology, v.5, n.1, p.18-32, 1991. DOI: https://doi.org/10.1111/j.1523-1739.1991.tb00384.x

SIGNOR, D.; ZANI, C. F.; PALADINI, A. A.; DEON, M. D.; CERRI C. E. P.. Estoques de carbono e qualidade da matéria orgânica do solo em áreas cultivadas com cana-deaçúcar. Revista Brasileira de Ciência do Solo, v.38, n.5, p.1402-1410, 2014. Dol: http://dx.doi.org/10.1590/S010006832014000500005

SILVA JÚNIOR, M. C.. 100 Árvores do cerrado: guia de campo. Brasília: Rede de sementes do cerrado, 2005, 278 p.

SILVA, A. S.; SILVA, I. F.; BANDEIRA, L. B.; DIAS, B. O.; SILVA NETO, L. F.. Argila e matéria orgânica e seus efeitos na agregação em diferentes usos do solo. Ciência Rural, v.44, n.10, p.1783-1789, 2014. Dol: http://dx.doi.org/10.1590/0103-8478cr20130789

SOUZA, E. D.; COSTA, S. E. V. G. A.; ANGHINONI, I.; LIMA, C. V. S.; CARVALHO, P. C. F.; MARTINS, A. P.. Biomassa microbiana do solo em sistema de integração lavourapecuária em plantio direto, submetido a intensidades de pastejo. Revista Brasileira de Ciência do Solo, v.34, n.1, p.79-88, 2010. DOI: http://dx.doi.org/10.1590/S0100$\underline{06832010000100008}$
SOUZA, R. P. B.; FREITAS, M. A. M.; COSTA, M. P.; PEREIRA, L. F.; GOMES, J. V. A.. Impact of anthropic action on physical attributes of the soil in different physiology of Cerrado. Multi-Science Journal, v.1, n.9, p.28-32, 2017.

SPEROW, M.. Marginal cost to increase soil organic carbon using no-till on US cropland. Mitigation and Adaptation Strategies for Global Change, v.23, p.1-20, 2018. DOI: https://doi.org/10.1007/s11027-018-9799-7

STUMPF, L.; LEAL, O. A; PAULETTO, E. A.; PINTO, L. F. S.; REIS, D. A.; PINTO, M. A. B.; TUCHTENHAGEN, I. K.. Tensile strength and organic matter fractions in aggregates of a grass-covered mined soil under early stage recovery. Soil \& Tillage Research, v.176, p.69-76, 2018. DOI: https://doi.org/10.1016/j.still.2017.11.006

TISDALL, J. M.; OADES, J. M.. Organic matter and waterstable aggregates in soils. Journal of Soil Science, v.33, n.2, p.141-163, 1982. DOI: https://doi.org/10.1111/j.13652389.1982.tb01755.x

VIANA, V. M.; PINHEIRO, L. A. F. V.. Conservação da biodiversidade em fragmentos florestais. Série Técnica IPEF, v.12, n.32, p.25-42, 1998.

WADE, J.; CULMAN, S. W.; HURISSO, T. T.; MILLER, R. O.; BAKER, L.; HORWATH, W. R.. Sources of variability that compromise mineralizable carbon as a soil health indicator. Soil Science Society of America Journal, v.82, p.243-252, 2017. DOI: https://doi.org/10.2136/sssaj2017.03.0105

YEOMANS, A.; BREMNER, J. M.. A rapid and precise method for routine determination of organic carbon in soil. Communication Soil Science Plant Analysis, v.19, p.14671476, 1988. DOI: https://doi.org/10.1080/00103628809368027

A CBPC - Companhia Brasileira de Produção Científica (CNPJ: 11.221.422/0001-03) detém os direitos materiais desta publicação. Os direitos referem-se à publicação do trabalho em qualquer parte do mundo, incluindo os direitos às renovações, expansões e disseminações da contribuição, bem como outros direitos subsidiários. Todos os trabalhos publicados eletronicamente poderão posteriormente ser publicados em coletâneas impressas sob coordenação da Sustenere Publishing, da Companhia Brasileira de Produção Científica e seus parceiros autorizados. Os (as) autores (as) preservam os direitos autorais, mas não têm permissão para a publicação da contribuição em outro meio, impresso ou digital, em português ou em tradução. 